\title{
O sentido de comparação, o sentido do direito e o sentido do Brasil $\left(^{*}\right)$
}

\author{
Lino de Morais Leme
}

\section{PROÊMIO}

1. Tendo de fazer hoje um retrospecto de nossas atividades neste ano, lembrei-me de vos dizer algo sôbre $o$ sentido da comparação, o sentido do direito e o sentido do Brasil, falando assim, mais uma vez, a vosso espírito e a vosso coração.

\section{O SENTIDO DA COMPARAÇÃO}

2. Não é de hoje que se reconhece a necessidade da comparação, no ensino do direito. $O$ decreto n. 7.247, de 19-4-1879, art. $23, \S 5 .^{\circ}$, já determinava: "O estudo de direito constitucional, criminal, civil, comercial e administrativo, será sempre acompanhado da comparação da legislação pátria com a dos povos cultos".

Posteriormente, pelo decr. 1232 A, de 2-1-1891, foi creada nos cursos jurídicos a Cadeira de Legislação Comparada. Nela, na parte especial se estudavam geralmente o de 1942 .

$\left(^{*}\right)$ Preleção de encerramento de curso, feita em novembro 
direito civil, o comercial, o judiciário e o internacional privado, à luz da comparação.

Suprimida a Cadeira de Legislação Comparada, voltouse, implicitamente, ao regime anterior.

A reforma de ensino, de 1931, não restabeleceu a Cadeira suprimida, mas creou Cadeiras de direito comparado no curso de doutorado.

Qual a utilidade ou finalidade desse estudo?

3. Em trabalho que fez época, Edouard Lambert estuda "La fonction du droit civil comparé". A obra do ilustre escritor é orientada pela idéia de se formar um direito comum legislativo, que seria um conjunto de regras de aplicação universal, especialmente nos países civilizados.

Esse assunto já fôra frisado pelo eminente e saudoso professor desta Faculdade, JoÃo MonteIro, no discurso inaugural do curso de legislação comparada, em 30-5-1892, sob o tema - "Da futura universalização do direito". E posteriormente, na "Revista da Faculdade", em 1895, o sábio mestre retomou a matéria, em artigo intitulado "Cosmópolis do direito".

Será essa a função do direito comparado?

4. O anseio, a que se refere JoÃo MonteIro, é o manifestado por CícERo, o grande orador romano: "Nec erit alia lex Romae, alia Athenae; alia nunc, alia posthac; sed et omnes gentes et omni tempore una lex ex sempiterna et immutabilis continebit".

Para CícERo, portanto, a lei não seria apenas universal, mas igualmente imutavel. $\mathrm{O}$ direito não mais evolveria.

Escritores eminentes se fizeram pregoeiros da idéia. LAurent, cujas palavras Joño MonteIro cita, como corporificando a finalidade de seu trabalho, diz: "L'auteur n'a d'autre ambition que celle d'aller à la recherche des principes qui sont appelés à réaliser un jour l'idéal qu'un grand jurisconsulte a tracé à notre science, la communauté de droit entre les nations" (Droit civil int., 5; p. 306). 
E' o sonho de Napoleão, ampliado. O grande cabo de guerra pretendia unificar os codigos europeus. Não se satisfazem os espíritos com essa idéia, e querem unificar os codigos do mundo inteiro.

5. Essa tendência unificadora foi evidentemente influenciada pela orientação, geralmente seguida nos códigos, de se concederem aos estrangeiros os mesmos direitos que aos nacionais, bem assim pelo movimento em prol da unificação do direito nacional, na Suiça, na Itália e na Alemanha; - pelos trabalhos em prol da unificação de institutos de direito comercial, e especialmente pela orientação científica do direito. Sendo uma só a ciência, pensava-se, devem ser as mesmas as leis.

Não diremos que tambem influisse, no caso, o movimento operado em favor de uma lingua única, que suscitou tantas discussões e tanto esforço, culminando na elaboração de uma lingua artificial, destinada a se tornar a lingua universal.

Tambem devia ter influido, no desenvolvimento dessa idéia, a concepção do direito natural. Os gregos, dominados por seu espírito especulativo, desenvolveram o conceito de uma ratio naturalis: assim como ha uma ordem no Universo, assim tambem ha uma ordem na sociedade, e, ao lado da razão universal, ha a razão natural, da qual é um aspeto o direito natural. Os romanos se oricutaram, a respeito, em um tríplice sentido, que nos dão os textos de Gaio, Ulpiano e Paulo, unificados por Vínio. No direito moderno, diversas correntes apareceram, entre as quais a de Tonsen, que publicou, em 1828, um trabalho com o título - Máximas fundamentais de um direnito positivo universal, deduzidas de um princípio de direito natural.

6. Sem embargo da autoridade dos que defendem a idéia de um direito comum legislativo, não podemos com ela concordar. Pelo fato de se admitir que o direito seja 
uma ciência, não se pode concluir pela unidade universal das leis. Não se deve confundir as leis com os fatos ou os fenômenos. Como na ciência da linguagem ha as leis desta e os fatos da linguagem (morfológicos e sintáticos), da mesma fórma ha as leis da ciência do direito e os fatos jurídicos, dos quais as normas juridicas são como que a gramática.

Os fenómenos fisicos, químicos e biológicos não são idênticos nem nas regióes situadas no mesmo paralelo e no mesmo meridiano. Variam de acordo com o meio, embora sujeitos às mesmas leis; e a adaptação ao meio é uma lei fundamental nas ciências biológicas e sociais, pois sem ela não haveria nem sociedade, nem vida.

7. O homem varia constantemente, formando raças e variedades, que nitidamente se distinguem. A adaptação ao meio determina modificações de tal ordem, que, num mesmo país, se distinguem os habitantes de uma região dos de outra. E as modificações físicas são acompanhadas de outras, de ordem psíquica e sentimental. Variam os costumes, as idéias, os sentimentos, as aspirações. Não é a mẹma a vida. E o estado de civilização difere de povo para povo, ou ao menos de raça para raça.

Examinemos a condição da mulher e a do filho, em diferentes povos - o europeu, o muçulmano e o eslavo, por exemplo, e veremos a confirmação desse asserto.

Essa diversidade de costumes e de julgamentos morais levou Westermarck a se consagrar aos estudos sociológicos.

8. Dessa variedade de costumes não podia deixar de se originar a diversidade de leis, o que levou Aulo GÉlıo a dizer - "Leges .. ut facies coeli et maris varientur" — As leis variam, como a abóbada celeste e a superfície do mar.

O mesmo poderia ele dizer das linguas.

A existência da ciência da linguagem não levou a uma lingua universal. Da mesma fórma, a ciência do direito não tem, como consectário, o direito universal. 
9. Os próprios defensores desse direito reconhecem a impraticabilidade da idéia, quando, como JoÃo MonteIro, declaram: "Unificar não é homogenizar. Batemo-nos pela unificação do direito, sim; mas tambem queremo-lo tão ductil à ação das influências transitórias, que cada vez se heterogenize mais".

O senso da variabilidade das instituições juridicas é tão vivo, que ConsentinI, publicando um trabalho sobre "Le Droit de Famille, Essai de réforme", em que liga o estudo do direito comparado ao problema da unificação do direito privado, faz preceder o seu livro do "Exposé des motifs et résolutions sur l'unification dès législations", aprovado pela comissão internacional de jurisconsultos americanos, e, no entanto, escreve: "...chaque peuple a son milieu social particulier, ses. coutumes, ses habitudes de vie et de moralité, de sorte que, tout en respectant certaines règles fondamentales universelles, qui sont une condition indispensable de toute vie en société, le Droit Civil acquiert sa physionomie propre et devient le patrimoine exclusif et caractéristique d'une nation."

Com efeito, se ex facto oritur jus, significa isso, como salienta o mesmo autor, que o "Direito nasce da vida social, transforma-se com a vida social e deve adaptar-se à vida social".

10. Que o Direito seja uma ciência, é ponto incontroverso. Mas, o direito comparado tambem será uma ciência? E, no caso afirmativo, será uma ciência natural ou uma ciência social?

E' conhecida a controvérsia que tem havido em considerar-se, ou não, o direito como um organismo. E mesmo entre os adeptos dessa opinião, ha os que o dizem idêntico (SPEncer), os que apenas semelhante (Сomte) ou análogo (Letourneau) aos organismos vivos.

Não vamos entrar na questão. Baste-nos recordar que a classificação do direito como ciência social tem resistido. 
a todas as críticas, por fórma a se poder considerar hoje matéria pacifica.

Brider diz que uma nova ciência jurídica veiu à luz na segunda metade do seculo XIX. E que ela surgiu na França, com a creação da sociedade da legislação comparada, em 1896, sendo precursor dessa nova ciência ANTOINE DE SaInt Joseph, que alguns anos antes publicara a "Concordância entre os códigos civís estrangeiros e o Código Napoleão".

O direito comparado não é uma ciência, mas constitue argamassa para a ciência do direito. $O$ pensamento de considerá-lo ciência é fruto de uma epoca que pretendia fazer ciência de tudo, inclusive da arte de envelhecer, a que denominaram - "macrobiótica".

11. Com efeito, nas ciências sociais a indução se faz pela observação científica, a experimentação e a comparação; e, dadas ao deficiências dos dois primeiros processos, assumiu grande relevância o terceiro, a ponto de se denominar de método comparativo o aplicado ao estudo dos fenômenos sociais.

A linguagem é um fenomeno social, que serve para evidenciar a importância da comparação. As leis de glotologia resultam da comparação das linguas, como as das ciências físicas e naturais da observação dos fenômenos respetivos. Em um ensaio de glotologia, que publiquei, penso ter induzido uma nova lei glotológica - a da evolução de casos oblíquos para casos retos. Como procedi, para induzỉ-la? Observando o mesmo fato em várias línguas, e comparando-os - a evolução de casos retro para simples morfemas, devido a sincretismos verificados na conjugação, e o consequente aparecimento do pronome obliquo, com função subjetiva.

Como as línguas constituem a argamassa, com que trabalha o glotólogo, as varias legislações são a argamassa do jurista.

12. Sendo assim, como pode o direito comparado constituir uma ciência? O absurdo é tão grande como o preten- 
der-se que a comparação das linguas constitua uma ciência. Do fato de a comparação ser o meio por que se induzem as leis da linguagem, pensou-se em denominar filologia comparada à ciência da linguagem (Sayce). Analogamente se poderia chamar legislação comparada, ou direito comparado, à ciência do direito. Não, porém, pretender que haja uma ciência do direito comparado ao lado da ciência de direito. Seria confundir o método com a ciência. $O$ direito comparado não tem verdades gerais, necessárias e absolutas, distintas das que constituem o assento da ciência do direito.

13. Se o direito comparado não pode servir para a formação do direito legislativo universal, se ele não é uma ciência, nem por isso o seu estudo deixa de ter importância. Bastaria, para isso, constituir ele o método, para a ciência, e justificadas estariam as palavras de Gaudenzi (Lingua $e$ Diritto, apud J. MonteIro, p. 61): “Chi sa una sola lingua, non ne sà nessuna, diceva GoEthe; e si potrebbe dire ugualmente: chi sa un solo Diritto non ne sa alcuno".

Mas o direito comparado é ainda meio de enriquecimento ou melhoramento do direito. Assim como as línguas se influem reciprocamente, e ganham vida nova nesse intercâmbio, o direito conquista novas forças ao influxo recíproco que se exercem os sistemas legislativos.

Por isso muito acertadamente estabelecem os estatutos de uma sociedade alemã — "A Sociedade de legislação comparada tem por objeto o estudo das leis dos diferentes países e a investigação dos meios práticos que melhorem os diversos ramos de legislação."

14. Não se limitam a essas as vantagens do estudo do direito comparado.

Ele trás ainda, para o filósofo, o conhecimento das tendências imutaveis da natureza humana. O político conhece, através dele, o progresso a que atingiram outros povos, o resultado da implantação de certas instituições, a neces- 
sidade de promover a reforma dos costumes como base para a reforma legislativa. O historiador encontra aí largo subsídio, remontando do corpo de leis à organização social que o modelou, e advinhando, nas modificações efetuadas, as lutas sociais que as determinaram. O juiz vai encontrar, no direito comparado, elementos para interpretar o direito pátrio e suprir-lhe as deficiências. E o jurista vê, nesse estudo, o conhecimento de fenômenos juridicos que o guiam no estabelecimento das leis formadoras da ciência do direito.

Esse estudo é ainda mais necessário na época atual, quando se examina

\section{O SENTIDO DO DIREITO}

15. Que se observa no mundo moderno?

- A luta entre dois princípios: o que suprime a soberania do povo e o que a conserva,

- A preocupação de subordinar integralmente o direito à moral,

- A prevalência do interesse social sobre o interesse individual.

Ao meu espírito vem a idéia de que ha no mundo, em última análise, duas forças em luta - a conservadora e a destruidora, como ha o bem e o mal, o vício e a virtude, o Céu e o inferno. Da luta entre elas resulta a evolução ou a involução. Os elementos se integram e se dispersam. Do pó se fórma o homem e ele volta a ser pó.

Não ha, como pretendeu Darmesteter para a ciência da linguagem, duas forças opostas - a conservadora e a revolucionária. Esta não quer a destruição, mas um progresso mais rápido; e aquela não quer a imutabilidade, mas se opõe ao rompimento com o passado. Quando as transformações se operam lentamente, temos a evolução; quando violenta ou rapidamente, a revolução. Isso mostrei ha tempos, em um trabalho sobre o carater evolutivo das línguas. 
16. Em alguns Estados se implantou o regime da tirania. Suprimiu-se a conciência individual. Converteu-se o indivíduo em instrumento do Estado. Ele não existe para o bem dos cidadãos, mas sim estes para o bem do Estado, que é encarnado no chefe, e quod principi placuit legis habet vigorem, é ele quem dita as leis. A função dos magistrados se anula, órgãos, que passam a ser, do novo príncipe. $O$ estômago deve fazer o que a cabeça lhe ordenar.

Ha outros Estados que conservam o princípio da soberania do povo. Neles ha tambem um chefe, um guia, um condutor, quando as circunstâncias impôem; se ele não corresponder às esperanças, outro toma-lhe o logar. Nas ocasiões graves, é mister um chefe forte, integralmente apoiado pelo povo. Mas, não se anula o indivíduo; cada um exerce livremente a sua atividade e os seus direitos. O Estado se acha acima dos indivíduos, mas não os absorve.

17... Bentham figurara o direito e a moral como dois circulos concêntricos - o do direito maior que o da moral. Não o disse ele, mas podemos compreender a zona intermédia como ocupada pela economia, para mostrar que o direito se apoia - ou na moral, ou na economia.

$\mathrm{E}$ aí vemos a luta entre ambas, procurando uma aumentar o seu círculo e outra a sua zona.

Desse prélio resulta o reflexo maior ou menor da moral sobre o direito, sob a fórma de proteção à bôa fé, de solução equitativa, de proibição de enriquecimento à custa alheia, de obrigações naturais, de direito natural.

RIPERT se manifesta contrário ao materialismo jurídico - que identifica com o direito positivo -, como ao direito natural - o direito que lhe opõe, originando-se da razão e advoga, como verdadeiro positivismo jurídico, a subordinação do direito à moral.

Razão não tem o grande escritor em identificar o direito natural com a razão, quando, pelo conceito de Paulo, ele é quod semper aequum ac bonum est, ou, a equidade, que, na definição de CuJácıo, é jus quod lex scripta proetermisit 
Em tal sentido, de se recordar que os códigos austriacos e português consideram o direito natural como fonte subsidiária da lei, e que o Código francês diz ser a razão natural a fonte de todas as leis. Podemos dizer que essa razão, fundada sobre dados da experiência, é não sómente a fonte, mas também o ideal, pelo aperfeiçoamento constante da idéia jurídica.

E razão igualmente não assiste àqueles que pretendem substituir a idéia de justiça, que visa o bem comum, pela idéia moral, que é essencialmente altruista. O direito tutela tambem o interesse econômico, que pode ser independente de qualquer interesse moral. A lei é o meio, para se alcançar um fim - a justiça.

Pretende-se, porém, ir além, adotando-se a teoria da imprevisão, ou a subordinação dos contratos à cláusula rebus sic stantibus, exagero evidente, pois a regra sobre o caso fortuito ou de força maior permite atender às hipóteses justas; e inovação inconveniente, por tornar frageis os contratos e permitir à chicana desenvolver sem peias a sua ação. Em matéria de serviço público, transige-se, pela necessidade do mesmo; mas, fóra esse caso, tem alguns países aplicado o princípio apenas ao contrato da empreitada, isso todavia a partir de uma certa percentagem, que é o limite polonês ter generalizado a exceção, não é bastante para aceitar a noivdade sem que se demonstre a improcedência dos graves argumentos contrários.

18. No conflito entre o interesse individual e o coletivo, invocam-se, para a prevalência deste, ora os superiores interesses do Estado, ora os sentimentos de solidariedade, ora a evolução. Ao direito em que preponderam os interêsses da coletividade, chamam direito social, por oposição ao direito individual; e a transformação do direito, à luz desses princípios, chama-se socialização do direito.

Não se deve confundir essa feição social do direito civil com o direito do trabalho, ou seja o contrato de trabalho 
erigido em ramo especial do direito, e cuja importância se póde aquilatar, lembrando-se que a Espanha tem um Código de Trabalho, desde 1926, e que entre nós se procura consolidar as leis trabalhistas, como base para o futuro Código.

A propriedade passou a ser função social. Outros dispositivos constitucionais subordinam o interesse individual ao interesse geral. E agora a lei de introdução ao Código Civil, que entrou em vigor a 24 de Outubro, prescreveu, no art. 5.': "Na aplicação da lei, o juiz atenderá aos fins sociais a que ela se dirige e às exigências do bem comum". Não sómente se elimina a vetusta vontade do legislador, com adotar a interpretação sociológica, como também se subordina a lei ao interesse coletivo.

19. Nessas palavras se vê o sentido da evolução juridica no Brasil.

Sejam, porém, quais forem as nossas opiniões, todas as divergências devem cessar, seguindo todos

\section{O SENTIDO DO BRASIL}

Na hora atual, sómente um sentido tem o Brasil: voltar os corações e os espíritos, a palavra e a ação, o trabalho e a orientação, para a luta e para a vitória.

Ha vinte e oito anos, uma luta tremenda se desencadeou, porque um governo colocou a sua ambição acima de seu tratados, que foram considerados farrapos de papel. Passam os anos, e um megalomaniaco, galgando o poder, nenhum valor dá à palavra empenhada, aos compromissos assumidos. $\mathrm{E}$ ao pé da montanha de sua ambição, planta a árvore do fanatismo e do ódio, a cuja sombra sacrifica a liberdade e a honra, o direito e a justiça.

Os adeptos do novo credo semeiam, com os seus braços, a morte, o terror, a desolação, e oprimem, com o tacão de suas botas, os povos que lhes resistiram e os que neles. acreditaram. 
Dir-se-ia que Belzebud se encarnara em um ente humano, e que ele repetira, aos seus legionários, as palavras que o cego de Bunhill Fields põe em sua bôca:

"To do aught good never will be our task,

"But to do evil our sole delight" -

Nossa tarefa nunca será fazer o bem; nossa única alegria será fazer o mal.

Não era possível hesitar entre Deus e Belzebud, a liberdade e a tirania, o amor e o ódio. $\mathrm{O}$ momento se apresentou quando foram violados a soberania do Brasil e os princípios de humanidade, com o torpedeamento repetido de navios em nossas aguas territoriais. $E$ o Brasil entrou na luta com o entusiasmo de um povo novo e forte, com a deliberação de quem conhece o inimigo e a certeza de quem está convencido da justiça de sua causa.

Vê-se, na guerra atual, claramente vista, a verdade do que escreveu SÊNEcA - Melius est civitatem regi a viro optimo quam a lege optima. E' melhor o povo governado por uma mão excelente do que por uma excelente lei. Com ef eito, homens perfeitos podem dar uma fórma bela à vida, por mein das piores instituições.

Quando Aristoteles previa a transformação da tirania em despotismo, mais uma vez ele se revelou profeta. Sómente faltava acrescentar o uso dos entorpecentes - a expulsão dos judeus, a conquista do mundo, e outros, para ter, nas palavras do sábio estagirita, no oitavo livro da Política, o retrato dos déspotas atuais.

Os governos despóticos se manteem por essa forma; por isso eles são um perigo para a paz do mundo, quando se instalam em um país civilizado, forte e poderoso. Basta lembrar, quanto à América, o dr. Francia, Rosas e Lopez.

O combate a esses governos é, pois, uma cruzada, que vai beneficiar tambem os povos sob o jugo de um poder que faz estiolarem os sentimentos de dignidade e de justiça. 
O Brasil se alistou na cruzada que visa restituir os povos ao governo de si mesmos. Ele devia fazê-lo, pelo ensinamento da história. Ele precisava fezê-lo, para defender a honra nacional.

D'aí o anseio geral pela atitude de nossa Pátria, e o entusiasmo cívico quando o governo satisfez os sentimentos do povo.

Já o toque de reunir se ouviu. A mobilização se processa em todos os campos de atividade. A mobilização dos espiritos fará crescer a chama sagrada. A ciência e a técnica consagram o melhor dos seus esforços para forjar as armas de combate. E' o Brasil em ação!

Dentro em pouco, ouviremos os toques dos clarins e o ruflar dos tambores. $\mathrm{E}$ as colunas dos descendentes daqueles heróis que expulsaram os holandeses, que desbravaram os sertões, que são os guardas das fronteiras, que defenderam a honra da Patria, nas guerras que lhe foram impostas, passarão cantando os nossos hinos patrióticos, sob os calorosos aplausos dos que os contemplarem, com o riso nos lábios, os braços em gestos comoventes, as exclamações de alegria e confiança, e o olhar até perder de vista. Será o orgulho de ser brasileiro, a certeza da bôa causa, a esperança na vitória e a fé em que a liberdade e a justiça serão preservadas. $E$ os que ficarem dirão aos que partirem: o Brasil, nossa adorada Pátria,

\footnotetext{
"Este imenso, colosso, gigante,

"Trabalhai por erguê-lo de pé."
}

Será o Brasil em marcha.

$\mathrm{E}$ quando voltardes, vireis com as bandeiras desfraldadas, trareis as que tomardes ao inimigo, e, embora cobertos de pó, de suor, e de lama e alguns assinalados pela luta, cantareis, nos carros do triunfo, os hinos de exaltação à Pátria, dizendo: o Brasil,

"Este imenso, colosso, gigante, Trabalhei por erguê-lo de pé!" 
E sob a égide d'Aquele que é o eterno amor e a eterna justiça, e que do alto do Corcovado abençoa o Brasil, o gigante se erguerá para sagrar os nossos heróis, aqueles que formarão ao lado de Caxias, de Osório, de Barroso.

Será o Brasil vencedor! Será o gigante de pé!

$\mathrm{E}$ uns ao compasso das pancadas dos pêndulos das velhas catedrais, - "Nunca! Sempre! Sempre! Nunca!", outros aos dos pendulos que adornam os lares, - "Nunca! Sempre! Sempre! Nunca!", diremos:

Nunca seremos contra a liberdade!

Sempre seremos pela justiça!

Viva o Brasil! 